\title{
Educação Ambiental, Práticas e Políticas Curriculares na Graduação: Narrativas sobre Projetos Acadêmicos.
}

\author{
Enviromental Education, Pratices and Curriculum Polices at \\ Graduation: Narratives on Academic Projects.
}

\section{Luiza Rodrigues de Oliveira ${ }^{1}$; Maylta Brandão dos Anjos ${ }^{2}$; Rose Mary Latini ${ }^{3}$; Maria Bernadete Pinto dos Santos ${ }^{4}$.}

1 Doutora, Universidade Federal Fluminense, Niterói, Rio de Janeiro, Brasil-luiza.Oliveira@gmail.com/ http//orcid.org/0000-0003-2264-1258.

2 Doutora, Instituto Federal do Rio de Janeiro; Universidade Federal do Estado do Rio de Janeiro, Brasil maylta.anjos@ifrj.edu.br/http//orcid.org/0000-0001-6272-5056.

3 Doutora, Universidade Federal Fluminense, Niterói, Rio de Janeiro, Brasil - roselatini@id.uff.br/ http//orcid.org/00000001-9843-8462.

4 Doutora, Universidade Federal Fluminense, Niterói, Rio de Janeiro, Brasil -mariabpds@id.uff.br,/ http//orcid.org/00000002-0389-245X.

Palavras-chave:

Educação Ambiental.

Práticas Educacionais.

Políticas Curriculares.

\section{Keywords:}

Environmental education.Educational practices.Curriculum policies.
RESUMO: Este ensaio versa sobre o desenvolvimento da Educação Ambiental nas políticas e nas práticas curriculares para cursos de graduação. Para tanto, discutimos narrativas sobre um projeto de licenciatura em química e sobre um de bacharelado em psicologia. Levantamos algumas temáticas que consideramos importantes no cenário atual, em que conquistas e avanços no campo da Questão Ambiental, incluindo a Educação Ambiental, vêm sofrendo esvaziamentos e retrocessos no país. Destacamos a arena de disputa política entre as forças que concebem a Educação Ambiental pelo viés crítico-social e a outra que propõe uma ação conservadora e consensual. O currículo é cabo de força nesse debate que reacende a discussão das novas políticas e proposições governamentais. Portanto, re-pensamos, nesse breve espaço, a inserção dessa temática no entrelaçamento do ensino, da pesquisa e da extensão, na formação em psicologia (bacharelado) e em química (licenciatura), tendo por base as memórias das pesquisadoras do LALIDH/UFF Laboratório de Estudos Interseccionais da Linguagem e do Desenvolvimento Humano - no encontro com alunas de uma escola da Educação Básica.
ABSTRACT: This essay deals with the development of Environmental Education in curriculum policies and practices for undergraduate courses. To this end, we discuss narratives about a degree project in chemistry and about a bachelor's degree in psychology. We raised some themes that we consider important in the current scenario, in which achievements and advances in the field of Environmental Matters, including Environmental Education, have been suffering hollows and setbacks in the country. We highlight the arena of political dispute between the forces that conceive Environmental Education from a critical-social perspective and the other that proposes a conservative and consensual action. The curriculum is a force in this debate that reignites the discussion of new government policies and proposals. Therefore, we re-think, in this brief space, the insertion of this theme in the intertwining of teaching, research and extension, in training in psychology (bachelor's degree) and in chemistry (degree), based on the memories of the researchers from LALIDH / UFF - Laboratory of Intersectional Studies of Language and Human Development - at the meeting with students from a Basic Education school. We are a family owned and operated business. 


\title{
INTRODUÇÃO
}

\section{Re-dizer o dito ...re-escrever o escrito... Pravda!!!}

\begin{abstract}
Falar do dito não é apenas re-dizer o dito mas reviver o vivido que gerou o dizer que agora, no tempo do redizer, de novo se diz. Redizer, falar do dito, por isso envolve ouvir novamente o dito pelo outro sobre por causa do nosso dizer [...] mas se as ideias, as posições a explicitar, a explicar, a defender no texto, vierem sendo partejadas na ação-reflexão-ação em que nos envolvemos, tocados por lembranças de ocorridos em velhas tramas, o momento de escrever se constitui como um tempo de criação e de re-criação, também, das ideias com que chegamos á nossa mesa de trabalho. O tempo de escrever, diga-se ainda, é sempre precedido pelo de falar das ideias que serão fixadas no papel. Pelo menos foi assim que se deu conosco. Falar delas antes de sobre elas escrever, em conversas de amigos, em seminários, em conferências, foi também uma forma de não só testá-las, mas de recriá-las, de repartejá-las, cujas arestas poderiam ser melhor aparadas quando o pensamento ganhasse forma escrita com outra disciplina, com outra sistemática. (FREIRE, 2003, pp. 17 e 54$)$.
\end{abstract}

Foi assim, tal como Freire, re-dizendo o dito, vivendo as práticas, que levamos cerca de dois anos exercitando o tempo da oralidade sobre as dúvidas e as zonas de sentidos relativas aos nossos projetos de pesquisa em Educação Ambiental. Acreditamos que reescrever é também revisitar ideias, fazer da prática a ação posta à reflexão, que está sempre em devir, em um entrelaçar de tempos. No percurso historiográfico sobre o qual repensamos a ação humana sobre a natureza, a ciência está presente e não prescinde de tempo, análise e revisitação.

Escrever este texto hoje, tempos depois da finalização do último desses projetos, não significa que eles estiveram esquecidos, mas que precisaram ser reinventados na oralidade do cotidiano: nas nossas aulas, nas nossas orientações, nos encontros com os nossos pares, nos encontros com as populações de cenários diversos. Não se trata de um exercício de memória a fim de "descobrir" um sentido que lá sempre esteve, mas de uma experiência em que a dialogia das interpelações cotidianas nos ajuda a constituir a pesquisa, o ensino e a extensão como processo. Chamamos de interpelação, aquilo que, a partir da escuta e da intervenção do outro, nos põe em movimento, é o que Bakhtin (2012) nomeia de réplica, de interpretaçãocompreensão, que se realiza a partir de uma posição exotópica, extralocalizada, que leva a refletir sobre o vivido, a pensar, a reconstruir e a analisar, pondo em revista o sentido do estabelecimento da crítica e autocrítica, caminhos de um re-fazer.

Exercitando a oralidade, a dialogia, a réplica, re-dizemos, neste ensaio, uma cena dos nossos projetos de Educação Ambiental para pensar a inserção da Questão Ambiental, no 
entrelaçamento entre ensino, pesquisa e extensão, na formação em psicologia (bacharelado) e em química (licenciatura). Re-dizemos, re-vivemos, então, as memórias do nosso grupo de pesquisa, acerca das relações concretas desses projetos. Pautamos em questões e olhares que racionalizam e interpelam a ação posta num caminho de possibilidades mais amplas, participativas e inclusivas da Questão Ambiental.

Os projetos que temos desenvolvido no LALIDH-UFF (Laboratório de Estudos Interseccionais da Linguagem e do Desenvolvimento Humano) não se constituem apenas como espaço de pesquisa, mas também espaços de ensino e extensão, pois é lugar de formação para estudantes do Bacharelado em Psicologia e da Licenciatura em Química e, igualmente, de estudantes da Educação Básica e dos alunos do Programa de Pós-Graduação em Ensino de Ciências da Natureza e do Programa de Pós-Graduação em Psicologia; e, ainda, realiza ações dirigidas à sociedade.

Cremos que as ações e discussões travadas nesse espaço perfazem caminhos para a constituição de sujeitos de ações que se consolidam nos seus fazeres e se recolocam nas cenas com seus saberes e forças transformadoras. Pautamos o início das discussões naquilo que nos causa incômodo, e que mobilizam para um re-dizer e re-pensar, colocando de forma singular o olhar de cada um. Como recorte de análise, neste ensaio, discutiremos a formação dos alunos do Bacharelado em Psicologia e da Licenciatura em Química, a partir de uma cena específica vivenciada em nossos projetos.

A perspectiva da formação em nível de Graduação (Bacharelado e/ou Licenciatura), tendo a Educação Ambiental como tema transversal, pode ser entendida pela legislação vigente. A Lei No 9795/1999 - Lei de Educação Ambiental, que institui a Política Nacional de Educação Ambiental, e apresenta como princípios básicos, dentre outros, o enfoque da crítica social, ou seja, a concepção de ambiente como uma interdependência entre o meio natural, o socioeconômico e o cultural, sob o enfoque da sustentabilidade, da interdisciplinaridade, da abordagem articulada das questões ambientais locais, regionais, nacionais e globais, o reconhecimento e o respeito à pluralidade e à diversidade individual e cultural (BRASIL, 1999)

Nessa matriz de pensamento nos alistamos ao que contradiz o paradigma reducionista e fragmentado constado na literatura da ciência moderna. Colocamos em cena o paradigma ecológico nas suas novas propositivas, sobretudo, a partir do meado do século XX diante das grandes conferências internacionais, o Brasil tem no manifesto o "Fim do Futuro" (LUTZENBERGER,1999) colocações que fazem pensar o processo civilizatório pós revolução industrial.

Com o debate que começa a questionar o modo de vida americano, somos evocados para restituirmos um enlace que não verse apenas a temporalidade dos recursos naturais como 
o eixo principal da relação sociedade e natureza. A sociedade, na sua produção econômica, e nos modelos derivativos dela, começa a ser colocada em xeque. Os encontros internacionais, que acontecem a partir do início da década de 1960, põem em debate os limites do crescimento, apontam o grande flagelo deixado pela equação que não se fecha entre produção, trabalho e consumo.

Um dos debates que nasce dos encontros internacionais e se estabelece no pensamento ambiental a ser trabalhado nas escolas, por meio da Educação Ambiental, refere-se, sobretudo, à formação escolar, acadêmica e profissional. Essa formação, segundos os grupos envolvidos no corpo da questão, dará sentido filosófico a um saber que observa a natureza e o outro no princípio de alteridade que respeita limites e recomposições dos biomas e das sociedades vividas nele. Fatores como manutenção e sucessão de sistemas naturais são analisados na interligação sujeito e terra, sujeitos e territórios, sujeitos e formação. Por fim, sujeitos na ação no mundo, sujeitos na ação educacional, no ambiente e na sociedade.

Nesse palco, Freire (2003), Saviani (2011), Frigotto (2008), Silva (2000), Demo (2002), entre outros, nos movem a pensar a relação política entre educação e sociedade. Consolidam um pensamento que tem na educação ambiental repercussões sociais que amplificam o debate. Trazem a noção propositiva da dialética e dos diálogos participativos que encenam uma leitura sistêmica, anunciando o resgate fundamental a ser feito no equilíbrio entre humanidade e natureza. A Educação Ambiental é fundamento de ação. É um re-dizer e re-escrever o sentido de formação profissional e profissão, tal qual pretendemos fazer nesse espaço de interlocuções. É um re-pensar de novos planos de ação, sendo fiel à memória que compõe e recompõe cenas e cenários de movimentos agregadores.

A Questão Ambiental emerge como possibilidade de novas ações que fertilizam o debate na interpelação das dinâmicas socioambientais e políticas. Confronta a sociedade que transforma em chorume a sua produção através do descarte dos seus diferentes consumos nos lixões e aterros sanitários legais, ou não, situados nas periferias das cidades. O retrato dessa problemática requer um debruçar sobre princípios e objetivos que vão ao encontro das discussões oriundas dos novos modelos sociais e econômicos. É preciso, tal como nos diz o martinicano F. Fanon pensar as marcas da cidade partida em que “(...) a cidade do colono é uma cidade sólida, toda de pedra e ferro. É uma cidade iluminada, asfaltada (...) A cidade do colonizado (...) a aldeia negra, a Medina (...) é esfomeada de pão, carne, sapatos, de carvão, de luz (FANON, 2015, pp 55-6).

Há mais de quarenta anos essa problemática é tema dos encontros das nações desenvolvidas e em desenvolvimento, tendo como as mais emblemáticas, na esfera socioambiental, a Conferência de Tbilisi e também do Tratado de Educação Ambiental para Sociedades Sustentáveis e Responsabilidade Global, resultante das discussões do Fórum 
Global paralelo à Rio-92. Nessa perspectiva, as discussões afeitas à temática socioambiental, ainda necessitam ser atravessadas por conhecimentos multi e interdisciplinares, por metodologias que promovam um pensamento crítico, pela compreensão do contexto histórico e político e não exclusivamente por estratégias que objetivam discutir as questões ambientais pelo viés puramente técnico, convencional e conservador, de forma biocentrada, mantendo uma visão preservacionista de ambiente. Necessitamos, ainda, destacar o papel fundamental da Ciência no que está posto em termos de formulação teórica, ou seja, o campo da Educação Ambiental, hegemonicamente constituído por dois blocos políticos pedagógicos, o conservador e o crítico. Para Loureiro,

Tais blocos dinâmicos (conservador ou crítico) [...] definiram-se, no que se refere à compreensão de mundo e sociedade, a partir da apropriação de dois métodos que, independentemente da "questão ambiental" ser um objeto de interesse direto ou não, se estruturaram em cima de categorias centrais para a perspectiva ambientalista (integração, totalidade, processos, movimento, relações, entre outras). Em termos gerais, o primeiro bloco mencionado está fortemente influenciado [...] pelo pragmatismo ambientalista da proposta de "alfabetização ambiental" norteamericana. E o segundo, mais inserido nos debates clássicos do campo da educação propriamente dita, pela dialética em suas diferentes formulações de orientação marxista ou em diálogo direto com esta. (LOUREIRO, 2006, p.1476)

É fundamental entendermos a Educação Ambiental Crítica como uma conquista da Ciência, mas naquilo que hoje esse tipo de conhecimento traz de mais inovador, a interpelação que recebe dos Movimentos Sociais. Estamos, assim, propondo uma Educação Ambiental aterrada, em que a formação subjetiva se dá pela localização, pelo espaço pela cultura e pela identidade. Milton Santos (2001), geógrafo brasileiro, nega o território apenas natural, para apresentá-lo como dinâmico, que é constituído pelas características físicas de área e, também, pelas marcas deixadas pelo homem. Marcas que não podem ser, por nós especialistas, levantadas e diagnosticadas pelo olhar de fora, mas que só podem ser afirmadas por aqueles que lá habitam. Produz-se uma verdadeira esquizofrenia, já que os lugares escolhidos acolhem e beneficiam os vetores da racionalidade dominante, permitindo a emergência de outras formas de vida. Essa esquizofrenia do território e do lugar tem um papel ativo na formação da consciência. (SANTOS, 2001, p. 80). Santos insiste no protagonismo atuação dos excluídos nas novas formas de comunicação e de ações para mudar as suas próprias vidas. Assim, não cabe aos especialistas falarem, diagnosticarem sobre e sim atuarem com as populações. "Essa é a aposta na construção dos serviços substitutivos territoriais. Ele seria formado pelo conjunto indissociável do substrato físico, natural ou artificial, e mais o seu uso, ou, em outras palavras, a base técnica e mais as práticas sociais, isto é, uma combinação de técnica e política" (SANTOS, 2001, p. 87).

Essa proposta caminha em contramão à ordem institucional vigente que usurpa bandeiras humanistas de crítica social, que trazem o povo como protagonista, principal ator, 
na sua agência, do enredo ambiental. Entretanto, um discurso escamoteador prepara uma "cortina de fumaça" formada para confundir e subtrair as principais pautas dessa luta que se ergue, também, na visão crítica aos flagelos que negam o território em suas marcas deixadas pela colonização, sistemas exploradores da vida e da força humana de trabalho, gerando a necropolítica (MBEMBE, 2018) e as dicotomias entre humanidade, política, sociedade e natureza. Esses efeitos, mascarados, necessitam ser problematizados e reacendidos no agenciamento dos povos e por eles, como Santos (2001) afirmou. Por isso, as práticas de ensino não podem se dar na preposição "sobre", mas na preposição e na ideia de "com" os sujeitos, que na pele sentem, vivem e respiram essa dor no seu lugar, espaço, território e tempo.

Ao que pese esse pensamento, vemos que nas práticas de ensino o viés conservador da educação ambiental ainda é muito presente (TRAJBER e MENDONÇA, 2006), sobretudo, na formação de profissionais que atuam nos cursos de bacharelado e nos de licenciatura. No caso específico do Ensino de Química, a pesquisa realizada por Latini e Sousa (2011), sobre práticas de ensino de química articulada à temática ambiental, aponta que somente a partir de 2009, essas, lentamente começam a apresentar um ensino de Química e Ambiente que caminha para superação de uma visão preservacionista do ambiente, incorporando as dimensões históricas, sociais, políticas e econômicas. Nos cursos de Psicologia, as ações vêm, surpreendentemente, apostando em modelos comportamentalistas; é surpreendente porque a psicologia no Brasil se constitui por um campo teórico que afirma a subjetividade e seus entrelaçamentos histórico-culturais (MELO, 1991).

Dessa maneira, temos observado nas ações que interseccionam psicologia e Educação Ambiental e/ou Educação Ambiental, um distanciamento entre teoria e prática, discussões e práticas comportamentalistas, em que a subjetividade e a identidade são retiradas de cena, com as seguintes conseqüências: dissociação entre currículo e identidade, fragmentação do ensino, ausência dessa discussão na formação docente inicial e continuada, distanciamento Escola e Universidade, dentre outros.

A discussão que realizamos neste ensaio não se dá pela análise do cumprimento de uma lei, mas instiga a pensar as formulações teóricas e resultadas de pesquisas dadas pela vivência, pelo exercício do ato nas ações de ensino, pesquisa e extensão, em que identificamos exatamente as consequiências de uma Educação Ambiental preservacionista, comportamentalista, tal como dizemos acima. $\mathrm{O}$ ofício que nos move a abrir, em sintonia e intuição, um saber específico, se volta para as lacunas que devem ser pensadas, ditas, passadas a limpo num crivo de ações estruturadas, na contramão do que amalgama currículos distantes e distópicos das demandas socioambientais. 
Apostamos na práxis que conduziu e conduz princípios e valores de igualdade, participação política, defesa pela justiça equânime e democrática, rompendo com paradigmas comportamentalistas e conservadores que imperam num instrumental teórico tradicional que se opõe ao movimento de novos ventos e fortalece narrativas curriculares que vão ao encontro de um posicionamento a favor do abraço que não estigmatiza e fragmenta as cenas, mas antes busca a compreensão no campo formador das ideias.

O que isso significa? É uma aposta na singularidade do ato e na transformação, na produção do novo, do instituinte. É a ruptura com a naturalização do vivido, com a abstração do concreto, que nos leva a ingenuidade da "mera aplicação da lei e dos conceitos". É preciso trazer à cena o ato singular para que lei, fatos abstratos, conceitos não sobreponham à vida, à existência. Desenvolver Educação Ambiental pensando apenas em aplicações de leis e de conteúdos desarticulados da vida concreta é um ato de extrema violência. Fanon fala dos intermediários da violência, daqueles que entendemos como as instituições, que seja na rua ou na escola, controlam, vigiam, desumanizam corpos e subjetividades, e mais, negam direito à identidade. "O intermediário não alivia a opressão, não disfarça a dominação. Ele as expõe, ele as manifesta com a consciência tranquila das forças da ordem. O intermediário leva a violência para as casas e para os cérebros dos colonizados (FANON, 2015, p. 55). E a Escola e a Universidade com suas apostas comportamentalistas e conteudistas podem ser esse "intermediário" que denuncia Fanon.

Para fazer diferente é preciso ações de "descolonização". Descolonizar para Fanon é construir formas de reconexão com as origens, para que se possa romper com o lugar de objeto em que os mais vulneráveis são colocados, para romper com um sistema colonial de opressão. Cultura, segundo Fanon, é a transformação da violência sofrida em violência organizada como luta de libertação, de superação. "A descolonização é verdadeiramente a criação de homens novos. Mas essa criação não recebe a sua legitimidade de nenhuma potência sobrenatural: a "coisa" colonizada se torna homem no processo mesmo pelo qual ele se liberta" (FANON, 2015, p. 53).

A vertente ambiental é rica de nuances, polissemias, complexidade e atua num campo de rompimento aos paradigmas redutores que não tenham a vida como a proteção e como moeda maior. Nela, novo valor é formado e assemelha-se a criação de novos afetos que têm na crítica ao modelo econômico a tônica precursora. A busca de um argumento a favor da vida cresce na narrativa, num re-dizer que a natureza não depende da humanidade, sobreviverá aos danos que a civilização moderna tem causado. Mas a essa civilização, restará a sua autodestruição. Por isso, no discurso ambiental evoca-se mudança estrutural. Essa transcende comportamento, costumes, moralidade, concessões, convenções, acertos comerciais, negociações. É ato de profunda transformação. 
O levantamento dessa questão por si só já é crítica ao modelo impetrado pela economia hegemônica. Passa pela lógica da crítica social à espoliação e à expropriação dos recursos, do trabalho humano, do equilibro distante entre humanidade e natureza. Em Ingold (2012) vemos que a narrativa que compõe outros quadros culturais são e estão entrelaçados com a Questão Ambiental no seu processo de formação. Assim, em suas palavras

\begin{abstract}
Habitar o mundo, ao contrário, é se juntar ao processo de formação [...] Em suma, não pode haver vida num mundo onde o céu e a terra não se misturam. [...] Além disso, não se pode falar da terra sem pensar no céu, e vice-versa. Um partilha da essência do outro [...] O pássaro é o seu voar; o peixe, o seu nadar. [...] sociedade moderna, é claro, tem aversão ao caos. Mas por mais que ela tenha tentado, através da engenharia, construir um mundo material à altura das suas expectativas - ou seja, um mundo de objetos discretos e bem ordenados -, suas aspirações são constantemente frustradas pela recusa da vida em ser contida. Podemos pensar que objetos têm superfícies externas, mas onde quer que haja superfícies a vida depende da troca contínua de materiais através delas. Se, ao transformar a terra em superfície ou encarcerar corpos, nós bloqueamos essas trocas, nada poderá viver. Na prática, esses bloqueios só podem ser parciais e provisórios. A superfície dura da terra, por exemplo, talvez seja a característica mais saliente do que chamamos convencionalmente de "ambiente construído" [...] Onde quer que olhemos, os materiais ativos da vida estão vencendo a mão morta da materialidade que tenta tolhê-los. (INGOLD, 2012, pp. 27-9).
\end{abstract}

Há na crítica um componente de mudança que vê as 'coisas' entre iguais e complementares. No humano recupera dimensões da empatia, do sentimento que agrega, mostrando singularidades e propostas que podem e devem ser trabalhadas nas composições curriculares. Dentro da perspectiva colocada por Ingold (2012), no mundo das ‘coisas' elas formarão os sujeitos para uma intervenção não ingênua e não utilitarista do mundo. São essas questões que apontam para uma Educação Ambiental que constrói nas práticas e políticas curriculares da graduação novas narrativas sobre projetos acadêmicos que provoquem intervenções na realidade, não como espectadores e observadores de uma ciência neutra. Muito pelo contrário, mas em categorias socioambientais tratadas no seu aspecto crítico, complexo, participativo e dentro de um potencial de transformação, como já assinalado.

São essas categorias invocadas para composição de uma lógica curricular que sinaliza um ato singular para as narrativas que abrem passagem e fruição para a temática ambiental, no seu aspecto coletivo e volitivo de mudança estrutural, que atinja ao status quo. Na dialogia produzimos outra intenção ambiental que caminha em mão contrária ao aspecto dilapidador do mercado.

O que visamos foi construir, nesse ensaio, um texto resguardado do discurso fácil e conciliador diferente daquele que tem sido destinado a muitos campos da Educação Ambiental. Como nos diz Fanon (2015),

A descolonização, que se propõe a mudar a ordem do mundo é, como se vê, um programa de desordem absoluta. Mas ela não pode ser o resultado de uma operação mágica, de um abalo natural ou de um entendimento amigável (...) desmantelar o mundo colonial não significa que depois da abolição das fronteiras, serão construídas vias de passagem entre as duas zonas. Destruir o mundo colonial é, nem mais nem menos, abolir uma zona, enterrá-la no mais profundo do solo ou expulsála do território (pp. 52 e 57). 
Pautamo-nos, assim, não no consenso, mas na réplica ao que está posto. "O que não é possível é simplesmente fazer o discurso democrático, antidiscriminatório e ter uma prática colonial" (FREIRE, 2003, p. 68). Apresentamos, para isso, cenas das nossas memórias que dão concretude aos nossos projetos. É uma aposta numa certa torção da linguagem, que historicamente, na sociedade moderna, está a serviço da razão, do pensamento formalabstrato, estando, portanto, a serviço de transformar normas, leis, conceitos em fatos em si, a serviço de naturalizar o vivido. Narramos aqui dois momentos que foram fundamentais para o nosso entendimento de que Educação Ambiental não é consenso, mas, sim, "descolonização do ser" no sentido fanoniano e freiriano do termo.

Estamos exercitando a busca da verdade como pravda (BAKHTIN, 2012) que é o ato, o encontro com o outro e não a veracidade, o universalmente incontestável; é o que hoje chamamos saberes localizados e práticas concretas (FREIRE, 2003). Para tanto, o que nos move é um grande incômodo com o momento vivido, com a placidez dada. É urgente e inegociável a vida humana e planetária. À defesa delas as instituições devem se erguer, observando a linhas nada tênues que separam impactos ambientais e equilíbrio socioambiental. As instituições de ensino, nas suas composições curriculares, nos grupos de pesquisas, deverão ser voz em defesa da vida. Ainda que os conflitos, antagonismos e contradições nos toquem, não pode haver narrativas que façam crescer e alimentar a distopia na formação acadêmica. Em uníssono alegamos que as práticas e políticas curriculares na graduação devem compor um eixo a bem da sucessão da vida e a bem de projetos acadêmicos que deixem claro essa intenção.

\section{A narrativa...pravda!!!}

A construção das narrativas é um exercício de pravda, pois "não é possível [...] fazer o discurso democrático, antidiscriminatório e ter uma prática colonial [...] mudar a linguagem faz parte do processo de mudar o mundo. A relação entre linguagem-pensamento-mundo é uma relação dialética, processual, contraditória.” (FREIRE, 2003, p. 68). Por ser assim, assinalamos que este texto é um exercício de torção da linguagem e, portanto, de torção das nossas práticas. Não um exercício de apresentação de conceitos vazios, mas de construção de conceitos no exercício da concretude, que será trazida pelas cenas das memórias das autoras. É uma aposta na Educação Ambiental não esvaziada no reducionismo às suas leis, normas e diretrizes curriculares, é uma aposta em "não ser vencido pela força do desgosto de uma blablablá inconseqüente" (FREIRE, 2003, p. 73). Exercitamos, neste texto, uma escrita que não se pretende apenas arcabouço teórico, "blá blá blá inconseqüente", mas uma vivência para 
mudar as nossas práticas. Assim, ouvir as vozes das interpelações dos atores (alunos, professores) pode nos ajudar a experenciar a práxis. "Não é puro idealismo [...] não esperar que o mundo mude radicalmente para que se vá mudando a linguagem. Mudar a linguagem faz parte do processo de mudar o mundo. A relação entre linguagem-pensamento-mundo é uma relação dialética, processual, contraditória" (FREIRE, 2003, p. 68).

\title{
A Cena - a réplica ...pravda!
}

Narramos aqui uma única cena das vivências em nossos projetos de pesquisa, mas é uma verdade que não está apenas em um projeto, em um único acontecimento, está no vivido de nossas práticas. A cena, então, é pravda, é o encontro com o outro, com as populações, em nossos projetos.

\begin{abstract}
Chegamos num dia de quarta feira, às $14 \mathrm{~h}$, encontramos as quatro estudantes de uma das escolas da educação básica com a qual o nosso grupo de pesquisa interage. Tínhamos ido até lá para apresentar nosso projeto em Educação Ambiental. Começamos com slides que preparamos semanas antes. Falamos nós, professores da UFF. Os estudantes da graduação (naquele dia estavam os do bacharelado em psicologia), provocados pelos professores, também falaram. Ao final, após um longo silêncio, uma das estudantes da escola nos disse: "queremos mostrar uma coisa lá na nossa biblioteca". Fomos todos atender ao convite, as estudantes da escola à frente, nos apresentando os espaços, pátio, teatro, até chegar à biblioteca, onde nos levaram imediatamente às estantes nas quais estão livros de Vigotski, autor que afirmamos no início da conversa ser o referencial da pesquisa. Porém, a parada no teatro foi a mais longa, as estudantes relataram como se apropriaram daquele espaço, como ali "o palco é delas", em suas palavras.
\end{abstract}

Exercitando a linguagem para mudar nosso pequeno mundo, nossas ações em pesquisa, extensão e ensino, é preciso ouvir com atenção a réplica daquelas estudantes da escola básica à nossa completa falta de atenção aos saberes locais. Tomados (todos nós) pelos rigores e pelas ilusões da neutralidade científica, ficamos atônitos com o 'pedido', que aqui colocamos em suspensão não para negá-lo, mas para dizer que esse 'pedido' fez-se intervenção, interpelação ao nosso modo de fazer pesquisa e extensão. Pode parecer pouco, mas são as estudantes da escola, cenário das nossas ações de pesquisa e de extensão, inventando outro lugar, ou seja, não é sobre elas, mas é com os olhares e as vozes delas. E, ao fazer isso, aquelas estudantes nos 'exigiram' a invenção de outro lugar para nós, pesquisadores. E isso é muito!

Pensando a partir da nossa cena, nas possibilidades que ela nos dá de rearranjo do nosso modo de fazer pesquisa e extensão, entendemos que "[...] pesquisar com o outro implica tomá-lo não como "alvo" de nossas intervenções. Não se trata de tomar o outro como um ser respondente [...]" (MORAES, 2010, p. 29). Trata-se de assumir a interpelação, a réplica, aquilo que nos tira do lugar instituído de especialista e nos faz refletir sobre os nossos modos, pois como diz Freire (1986), “[...] Se me interessa conhecer os modos de pensar e os 
níveis de percepção do real dos grupos populares estes grupos não podem ser meras incidências de meu estudo" (p.35). É preciso ir ao encontro da realidade concreta das populações com as quais interagimos, realidade que só vivida pelo outro, só por ele pode ser contada, desvelada, trazida à cena e, portanto, transformada. Como nos diz Angela Davis (2017), é preciso escutar o que esta lá, não nas formas do nosso aprisionamento acadêmico, mas no vivido das populações. É o sentido de praxis que trazemos à cena, assim, não se trata de somente de um estudo teórico e diagnóstico, mas, sim, de promoção de práticas, que a partir da fala localizada das populações, instituem ações de Educação Ambiental que sejam formativas. Assim, não cabe aos especialistas falarem, diagnosticarem sobre, mas atuarem com as populações. “(...) em outras palavras, a base técnica e mais as práticas sociais, isto é, uma combinação de técnica e política” (SANTOS, 2002, p. 87).

Pensando, a partir daquela cena que se faz presente em nossas memórias, nas possibilidades que ela nos dá de, não apenas de mudar as formas de pesquisa e de extensão, mas também as de ensino, fazemos aqui um recorte e pensamos especificamente nas ações de Educação Ambiental. Os princípios básicos e os objetivos expressos na No 9795/1999 (BRASIL, 1999) não promovem uma Educação Ambiental crítica per se, que seja capaz de desenvolver uma sociedade mais sustentável. Contrariamente, muitas vezes, promove o engendramento de práticas conservadoras, pois desarticuladas da realidade concreta das populações. Esta afirmação não é uma fala contrária às leis, em hipótese alguma, mas é uma perspectiva de aterrá-las, de localizá-las. A simples referência, na legislação, à relação entre meio social, cultural e natural, da interdisciplinaridade, à valorização dos saberes locais, à diversidade não institui práticas de uma Educação Ambiental crítica. O que a põe em movimento é o exercício da dialética, da dialogia, da relação linguagem-pensamento-mundo.

\begin{abstract}
A prática preconceituosa de raça, de classe, de gênero ofende a substantividade do ser humano e nega radicalmente a democracia. Quão longe dela nos achamos quando vivemos a impunidade dos que matam meninos nas ruas, dos que assassinam camponeses que lutam por seus direitos, dos que discriminam os negros, dos que inferiorizam as mulheres (...) A mim me dá pena e não raiva, quando vejo a arrogância com que a branquitude de sociedades em que se faz isso (...) se apresenta ao mundo como pedagoga da democracia (FREIRE, 2002, pp. 201).
\end{abstract}

Voltando a nossa cena, podemos entender que a Educação Ambiental como tema transversal no ensino da graduação, no caso específico do nosso ensaio, no ensino da Licenciatura em Química e no Ensino do Bacharelado em Psicologia, não é possível a centralização em práticas típicas do pragmatismo ambientalista, com uma proposta de “alfabetização ambiental" norte-americana, como nos diz Loureiro (2006). Não se trata de abandonar as perspectivas naturalistas, em prol de ações puramente ativistas, mas de exercitar dialogia. 
Freire (2003) nos diz que é preciso recusar a compreensão da consciência como puro reflexo da realidade material, mas é preciso também recusar a ideia de que a consciência tem poder determinante sobre essa realidade.

$\mathrm{Na}$ Licenciatura em Química tem sido lugar comum o desenvolvimento de ações pedagógicas que desassociam teoria e prática, ambiente e sociedade, experimentos de laboratório e realidade concreta. E que mesmo práticas que incorporam as dimensões históricas, sociais, políticas e econômicas, o fazem muitas vezes numa perspectiva ilustrativa, como pano de fundo. São desenvolvidas práticas de Educação Ambiental nas quais o sujeito não entra em cena, nas quais conceitos são reproduzidos. Reprodução de conceitos não significa aprendizagem! Não significa "descolonização do ser”.

No caso do Bacharelado em Psicologia, em sua interface com a educação ambiental, temos visto, embora o aporte da psicologia no Brasil seja aqueles que dialogam com a subjetividade e com as questões histórico-culturais, práticas comportamentalistas diante da questão ambiental. Treinamento de comportamentos objetivos não significa aprendizagem!

Esses modos de trazer à cena a Questão Ambiental, dissociando teoria e prática, são atravessados por diferentes questões, uma delas a do currículo. No Brasil, as diretrizes curriculares atuais, seja para os cursos do ensino fundamental, do ensino médio ou do ensino superior, instituem compromissos com a dialogia, o que dá sentido para que a educação ambiental crítica seja um saber que possa mediar, em ações interdisciplinares, esse tipo de proposta.

Nos princípios e compromissos na formação em Psicologia expressos nas Diretrizes Curriculares Nacionais para os Cursos de Graduação em Psicologia (BRASIL, 2011), encontramos no Art. $3^{\circ}$, como um dos princípios da formação em psicologia: "V - atuação em diferentes contextos, considerando as necessidades sociais e os direitos humanos, tendo em vista a promoção da qualidade de vida dos indivíduos, grupos, organizações e comunidades". Essa perspectiva que visa à qualidade de vida não pode estar circunscrita ao campo da psicologia, não pode ser reduzida a práticas psicológicas individualistas. Ações em que uma Educação Ambiental crítica seja desenvolvida pode ajudar na aprendizagem do significado do coletivo, da realidade concreta, para uma prática mais comprometida com "as necessidades sociais e os direitos humanos".

Nas Diretrizes Curriculares Nacionais para os Cursos de Bacharelado e de Licenciatura em Química (2001), encontramos que o licenciado em Química precisa:

Ter interesse no auto-aperfeiçoamento contínuo, curiosidade e capacidade para estudos extra-curriculares individuais ou em grupo, espírito investigativo, criatividade e iniciativa na busca de soluções para questões individuais e coletivas relacionadas com o ensino de Química, bem como para acompanhar as rápidas mudanças tecnológicas oferecidas pela interdisciplinaridade, como forma de garantir 
a qualidade do ensino de Química. Ter formação humanística que permita exercer plenamente sua cidadania e, enquanto profissional, respeitar o direito à vida e ao bem estar dos cidadãos.

Novamente identificamos diretrizes para as quais a formação extrapola as competências técnicas e exigem o desenvolvimento de um profissional capaz de lidar com ações coletivas e interdisciplinares. Assim, também na formação para o futuro professor de Química da Educação Básica, a vivência em projetos de pesquisa e de extensão em que a Educação Ambiental crítica seja exercitada pode ser mediadora das aprendizagens necessárias para a formação anunciada.

As participantes da ação do projeto do Bacharelado em Psicologia, ao apresentarem a escola às pesquisadoras, reivindicam protagonismo e autonomia. Assim, a sua participação redireciona o projeto, fazendo entender que a essa ação soma-se conquistas. A Educação Ambiental é percebida, nessa cena entre o pessoal e o coletivo, abrindo muitas vertentes que ecoam em vitalidade dos movimentos de ensino, pesquisa e extensão que não são, estão e nem deverão estar apartados de lutas justas e dignificadoras da vida.

Aprendemos com a interpelação da cena aqui anunciada ser a práxis a real participação das diferentes populações, diferentes atores sociais, numa troca de conhecimento entre saber especializado (saber científico) e saberes locais (saberes das populações). Aprendemos que associar psicologia e química em um mesmo projeto não pode ser apenas para que a primeira explique os processos mentais e a segunda apresente os conteúdos que fundamentam a aprendizagem da questão ambiental. É muito mais do que isso - é a produção de um ambiente em que educador e educando sejam sujeitos no ato de aprender e ensinar. Ato que se dá pela interpelação do outro, pela provocação, pelo desassossego, pela dialogia.

As alunas da escola básica, protagonistas da cena que relembramos neste texto, anunciaram o seu saber acerca daquele espaço que é vivenciado por elas e não por nós, interpelaram a nossa fala de especialista e mudaram o rumo dos nossos projetos, das nossas pesquisas, das nossas aulas, das nossas escritas, mudaram o nome do LALIDH, que passou a ser nomeado de Laboratório de Estudos Interseccionais da Linguagem e do Desenvolvimento Humano. E como diz Freire, a palavra muda o mundo, "mudar a linguagem faz parte do processo de mudar o mundo (2003, p. 68).... mas essa é uma outra história...História que anuncia um caminho de porvir, de re-inscrição e novo dizer de quem entende as conquistas, mas está atendo ao que se deixou de fazer.

A memória aqui resgatada rompe com as práticas que alimentam o silenciamento dos sujeitos participantes dos nossos projetos acadêmicos. Ao trazermos uma cena, como achado maior dessa narrativa, lembramos que as estudantes da Escola Básica, ao nos apresentarem o espaço, deram uma longa parada no teatro. Isso, anos depois, nos interroga sobre o 
Ensino, Saúde e Ambiente - Número Especial, pp. 353-370, Junho. 2020

protagonismo, sobre o que aquelas meninas nos estavam ensinando naquele momento. Assim, vimos que aquele espaço, que escolhemos como apropriados às nossas narrativas, não era o escolhido ou o mais representativo para aqueles sujeitos que vivenciavam dia a dia o local. "O palco delas, era o teatro, a biblioteca. Outra escola que não conhecíamos. Da réplica à pravda!

\title{
CONSIDERAÇÕES FINAIS
}

\begin{abstract}
Neste sentido, escrever é tão re-fazer o que esteve sendo pensado nos diferentes momentos de nossa prática, de nossas relações com, é tão re-criar, tão re-dizer o antes dizendo-se no tempo de nossa ação quanto ler seriamente exige de quem o faz, repensar o pensado, re-escrever o escrito e ler também o que antes de ter virado o escrito do autor ou da autora foi uma certa leitura sua (FREIRE, 2003, p. 54).
\end{abstract}

A Educação Ambiental nas práticas e nas políticas curriculares da graduação foi o tema trabalhado neste ensaio, no qual buscamos trazer narrativas que se entrelaçam aos projetos vividos nos grupos de pesquisa do bacharelado de Psicologia e Licenciatura em Química, numa universidade pública brasileira. Dessa forma, pudemos perceber que vida, dignidade, lugar de fala e formação acadêmica compõem e anunciam o caminho de debates e questionamentos da questão ambiental no ensino, na pesquisa e extensão.

Movimentos a favor do ambiente são criminalizados e sob o discurso de que são "ideológicos" os pilares da educação ambiental são fustigados. Começa-se a adentrar nas universidades a discussão de uma composição curricular que caminha na contramão de um capital ambiental de sobrevida do Estado. A fala contra a luta os e ganhos ambientais acerca de sua resiliência é desintegradora das matrizes naturais. A luta científica de pravda nos mostra um desafio a ser enfrentado, diante de tantos outros que empuxam para trás os avanços socioambientais.

Uma nova palavra, um novo re-dizer há de transformar o que está posto no mundo cotidiano acerca da questão ambiental, porque somos soma de uma estrutura que se ergue nos tempos fazendo do presente um registro constituinte das batalhas. As verdades vão vertendo, por isso o afeto emanado dela faz re-escrever e re-fazer o que foi visto e pensado nos diferentes momentos da prática e políticas curriculares na graduação.

A interpelação da cena anunciada nos fez ver que a práxis se dá na real participação das diferentes populações, diferentes atores sociais, numa troca de conhecimento entre saber especializado (saber científico) e saberes locais (saberes das populações). Aprendemos que associar psicologia e química em um mesmo projeto não pode ser apenas para que a primeira explique os processos mentais e a segunda apresente os conteúdos que fundamentam a aprendizagem da questão ambiental. É muito mais do que isso - é a produção de um ambiente 
em que educador e educando sejam sujeitos no ato de aprender e ensinar. Ato que se dá pela interpelação do outro, pela provocação, pelo desassossego, pela dialogia.

Este ensaio enunciou um saber autônomo que é vivenciado pelos participantes do projeto na sua condição de protagonistas no cenário trabalhado pelos grupos de pesquisa acadêmica. Esses sujeitos, no exercício dialógico, em que estão presentes a réplica e a dialogia como elementos instituintes de um lugar de fala, interpelaram a fala de especialistas, pontuando serem protagonistas e conhecedores do seu lugar como espaço de sobrevivência e apropriação de saberes. Alteraram, assim, o norte dos nossos projetos de pesquisa e redirecionaram, por conta desse ato, as nossas escritas. Tal fato nos remeteu à ação de repensar as cenas vivenciadas, retomando o espaço na forma de agir com e pela natureza a favor da vida. Essa dinâmica é per si um encontro dialético em que paradigmas ambientais no sentido sistêmico, conexo e integrador propiciam maior liberdade e autonomia nas relações humanas.

Numa narrativa que expressa o pensamento de reconhecimento e justiça para pessoas e ambiente, a maior conquista desse caminho, no sentido singular, foi o rompimento de sujeições socioambiental. Numa só cena, as alunas se colocaram nas suas preferências e localizaram suas histórias dentro delas. Essas alunas, na condição de re-dizer, de estabelecer as réplicas e frisar a contradição, reacenderam outra enunciação que as recolocam no tempo atual e nas vertentes que, de fato, há que se perseguir.

A isso filiamos nosso ofício como docentes que percebem o sopro positivo do reescrever e revisar a história. De dar renovo ao que se tentou sepultar pelas opressões, repressões, silenciamentos e violências disfarçadas. A educação ambiental lançou luz sobre esse fato, proporcionando, no devir dialógico e dialético a fala, o lugar de fala propositado à conquista, à mudança e a consolidação de sujeitos, que não somente sofrem a ação, mas também a praticam no seu pleno vigor, reconstruindo e recriando um novo estar, ser e fazer num compromisso inegociável com a pravda no que ela admite de réplica, autonomia de pensamento e produção da verdade.

\section{REFERÊNCIAS BIBLIOGRÁFICAS}

BAKHTIN, M. Para uma Filosofia do Ato Responsável. São Carlos: Pedro 7 João Editores, 2012.

BRASIL. Lei No 9795/1999, de 27 de abril de 1999. Lei de Educação Ambiental. Brasília, DF, abril 1999. 
BRASIL. Resolução nº 5, de 15 de março de 2011. Institui as Diretrizes Curriculares Nacionais para os cursos de graduação em Psicologia. Brasília, DF, março 2011.

BRASIL. Parecer N. ${ }^{\circ}$ CNE/CES 1.303/2001. Institui Diretrizes Curriculares Nacionais para os Cursos de Química. Brasília, DF, novembro 2001.

DAVIS, A. Mulheres, raça e classe. São Paulo: Boitempo, 2017.

DEMO, P. Saber pensar. São Paulo: Cortez / Instituto Paulo Freire, 2002.

FANON, F. Os Condenados da Terra. $3^{\text {a }}$ reimpressão. Juiz de Fora: UFJF, 2015

FREIRE, P. Pedagogia da Esperança. Um reencontro com a Pedagogia do Oprimido. São Paulo: Paz e Terra Editora, 2003.

FREIRE, P. Pedagogia da Autonomia: saberes necessários à prática educativa. São Paulo: Paz e Terra, 2002.

FREIRE, P. Criando Métodos de Pesquisa Alternativa: aprendendo a fazê-la melhor através da ação'. BRANDÃO, Carlos (ORG.). Pesquisa Participante. São Paulo: Editora Brasiliense, 1986.

FRIGOTTO, G. A interdisciplinaridade como necessidade e como problema nas ciências sociais. Ideação. v.10, n.1, p. 41-62, 2008

GUIMARÃES, M.; VASCOCELLOS, M. das M. Relações entre educação ambiental e educação em ciências na complementaridade dos espaços formais e não formais de educação. Educar, Curitiba, n. 27, p. 147-162, Editora UFPR, 2006

INGOLD, T. Trazendo as coisas de volta à vida: emaranhados criativos num mundo de materiais. Horizontes Antropológicos, vol.18, no.37, p.25-44, 2012

LATINI, R. M.; SOUSA, A. C. Química e Ambiente: as articulações presentes na Revista Química Nova na Escola (QNEsc). Investigações em Ensino de Ciências , v16(1), pp. 143159, 2011.

LOUREIRO, C. F. B. Complexidade e Dialética: contribuições à práxis política e emancipatória em educação ambiental. Educação e Sociedade, v. 27, n. 94, p. 131-152, 2006

LUTZENBERGER, J. O fim do futuro: manifesto ecológico brasileiro. Porto Alegre, Editora Movimento, 1999.

MBEMBE, A. Necropolítica. São Paulo: n-1 edições, 2018.

MELO, R.G. Psicologia ambiental: uma nova abordagem da psicologia. Psicol. USP v.2 n.1-2 São Paulo 1991

MORAES, M. Pesquisar COM: política ontológica e deficiência visual. In: MORAES, M; KASTRUP, V. Exercícios de ver e não ver: arte e pesquisa com pessoas com deficiência visual. Rio de Janeiro: Nau Editora, 2010. 
TRAJBER, R.; MENDONÇA, P. R. (Orgs.). Educação na diversidade: o que fazem as escolas que dizem que fazem educação ambiental. Brasília: Secretaria de Educação Continuada, Alfabetização e Diversidade, 2006.

PRIGOGINE, I. As leis do caos. São Paulo: Editora UNESP, 2002.

SANTOS, M. Por uma outra globalização (do pensamento único à consciência universal). Rio de Janeiro: Record, 2001.

SAVIANI, D. Educação em diálogo. Campinas: Autores Associados, 2011.

SILVA, T. T. Currículo, universalismo e relativismo: uma discussão com Jean-Claude Forquin. Educação e Sociedade, v.21, n.73, p.71-78, 2000.

\section{SOBRE OS AUTORES}

LUIZA RODRIGUES DE OLIVEIRA. Psicóloga formada pela Universidade Federal Fluminense (1992), possui Doutorado (2003) e Mestrado em Educação (1998) pela Universidade de São Paulo. Professora do Curso de Graduação em Psicologia, professora do Programa Stricto Sensu em Psicologia e Professora do Programa Stricto Sensu em Ensino de Ciências da Natureza da Universidade Federal Fluminense Áreas de pesquisa: Ensino de Ciências e Educação Antirracista.

MAYLTA BRANDÃO DOS ANJOS. Doutora e Mestre em Ciências Sociais. Docente e pesquisadora de Programas de Pós-Graduação Stricto e Lato Sensu. Experiências na área de Educação, com ênfase em Ensino de Ciências, atuando principalmente nos seguintes temas: educação ambiental; sociedade, desenvolvimento sustentável e formação de professores. Professora da UNIRIO.

ROSE MARY LATINI. É Licenciada em Química (1987) e possui graduação em Química Industrial (1983). Possui doutorado (1998) e mestrado (1989) em Geociências-Geoquímica Ambiental. Todos os títulos obtidos pela Universidade Federal Fluminense. Atualmente é professora do Departamento de Físico-Química/UFF e do Mestrado Profissional em Ensino de Ciências da Natureza/PPECN (UFF), estando ligada à linha de pesquisa Ensino de Química. Na Universidade Federal Fluminense desenvolve pesquisas na área de Ensino de Química e Físico-Química Nuclear. Na área de Ensino de Química os principais interesses de pesquisa são Metodologias Participativas; Química e Educação Ambiental e Abordagem Histórico-Cultural.

MARIA BERNADETE PINTO DOS SANTOS. É Bacharel em Química pela Universidade Federal da Bahia (1976), possui mestrado (1981) e doutorado em Geociências-Geoquímica (1997) pela Universidade Federal Fluminense. Pós-doutorado na Universidade de Oklahoma (1999). Professora Titular do Departamento de Físico-Química da Universidade Federal Fluminense. Atua nas áreas de pesquisa: Ensino de Química e Geoquímica.

Luiza Rodrigues de Oliveira descreveu a cena que desenvolve o artigo e construiu a proposta de análise a partir de conceitos das obras de P. Freire, de M. Bakhtin e de L. Vigotski, além de ter 
realizado a discussão teórica dessa abordagem histórico-cultural em suas interfaces com autores e autoras como: F. Fanon, b. hooks, M. Santos, A. Davis. Fez também observações acerca da licenciatura em Psicologia. Maylta Brandão dos Anjos descreveu a Educação Ambiental Crítica e o diálogo da mesma com a abordagem histórico-cultural, em relação à cena descrita. Elaborou e desenvolveu discussões acerca do momento político atual, trazendo autores como F. Loureiro e A. Mbembe. Rose Mary Latini fez contribuições acerca do diálogo da Educação Ambiental Crítica com a obra de Bakhtin e da licenciatura em Química. Maria Bernadete Pinto dos Santos fez contribuições acerca da obra de Vigotski e da licenciatura em Química, tendo, ainda, organizado a formatação do artigo. 